\title{
Magnetic resonance spectroscopy in Alzheimer's disease
}

This article was published in the following Dove Press journal:

Neuropsychiatric Disease and Treatment

15 May 2013

Number of times this article has been viewed

Jonathan Graff-Radford'

Kejal Kantarci ${ }^{2}$

'Department of Neurology,

'Department of Radiology,

Mayo Clinic, Rochester,

MN, USA
Correspondence: Kejal Kantarci Mayo Clinic, 200 First Street SW, Rochester, MN 55905, USA

Tel +I 5072849770

Fax +I 5072849778

Email kantarci.kejal@mayo.edu
Abstract: Aging is the primary risk factor for dementia. With increasing life expectancy and aging populations worldwide, dementia is becoming one of the significant public health problems of the century. The most common pathology underlying dementia in older adults is Alzheimer's disease. Proton magnetic resonance spectroscopy (MRS) may provide a window into the biochemical changes associated with the loss of neuronal integrity and other neurodegenerative pathology that involve the brain before the manifestations of cognitive impairment in patients who are at risk for Alzheimer's disease. This review focuses on proton MRS studies in normal aging, mild cognitive impairment, and dementia, and how proton MRS metabolite levels may be potential biomarkers for early diagnosis of dementia-related pathologic changes in the brain.

Keywords: Alzheimer's disease, magnetic resonance spectroscopy, mild cognitive impairment

\section{Introduction}

Biomarkers of Alzheimer's disease (AD) are important for both early diagnoses and evaluating treatment effects. Three decades of research indicate that proton magnetic resonance spectroscopy (MRS) is a potential biochemical imaging marker in AD. The focus of this review is to discuss the role of proton MRS in Alzheimer's disease. MRS allows regional measurement of metabolites including myo-Inositol (mI), choline (Cho), $\mathrm{N}$-acetyl aspartate (NAA), and creatine ( $\mathrm{Cr}$ ). Cr is typically used as an internal reference to control for variability in measurement because it remains unchanged in AD. ${ }^{1-3}$ Other metabolites that can be measured with proton MRS with advanced MRS sequences and post-processing methods include gamma-Aminobutyric acid (GABA) and glutathione which may not be available in conventional clinical scanners and are not the focus of this review. MRS may serve to identify patients with AD before clinical symptom onset as well as help distinguish AD from other neurodegenerative disorders.

\section{Development of metabolic biomarkers for AD}

In 1992, Klunk et $\mathrm{al}^{4}$ demonstrated a decrease in the neuronal metabolite NAA on MRS on autopsy brain samples of patients with AD compared to controls. The lower NAA level correlated with the amount of plaque and tangle pathology. ${ }^{4} \mathrm{NAA}$ is considered a neuronal marker and is synthesized in mitochondria. ${ }^{5}$ Supporting the notion that NAA levels correspond to neuronal integrity, reduced NAA levels in cortical tissue from patients with AD demonstrated a correlation between NAA concentration and neuronal density. ${ }^{6}$ Decreased NAA seen in head trauma, seizure, or coronary artery bypass 
surgery can resolve after recovery., ${ }^{5,-9}$ Further, NAA levels decreased in $\mathrm{AD}$ show transient improvement with acetylcholinesterase inhibitor treatment. ${ }^{10}$ The neurofibrillary tangles pathology of $\mathrm{AD}$ follow a typical progression from limbic to neocortical areas as AD advances. ${ }^{11}$ Similarly, changes in NAA follow a regional pattern as disease advances. For example, $\mathrm{AD}$ patients show a regional decrease in NAA/Cr ratio in the superior temporal lobe and posterior cingulate voxels compared to controls, but mild cognitive impairment (MCI) patients do not show a decline in NAA/Cr as AD-related neurodegeneration has not yet extended to these regions. ${ }^{12}$ Medial occipital lobe AD pathology involvement typically occurs at the final stage of the disease. ${ }^{11}$ Therefore, it is not surprising that there is no regional decrease in NAA/Cr in mild $\mathrm{AD}$ in the occipital lobe while more advanced cases demonstrate decrease NAA/Cr ratio. ${ }^{12-14}$ Eventually, NAA changes become widespread and have been shown to involve the parietal, temporal, and frontal lobe. ${ }^{12,15-19}$ Decreased $\mathrm{NAA} / \mathrm{Cr}$ ratios are non-specific and can be seen in other types of dementia including normal pressure hydrocephalus and have even been reported in cognitive decline associated with acquired immunodeficiency syndrome (AIDS). ${ }^{20,21}$

In 1993, it was demonstrated that in addition to decreased NAA levels, AD patients have elevated myo-Inositol to creatine $(\mathrm{mI} / \mathrm{Cr})$ levels. ${ }^{13}$ While NAA is a neuronal marker, $\mathrm{mI}$ is associated with glia and elevated levels with glial proliferation. ${ }^{22,23}$ The finding of decreased NAA and elevated $\mathrm{mI}$ in $\mathrm{AD}$ has been confirmed in several studies. ${ }^{12,16,24}$

The role of choline metabolite in AD is more controversial. A number of studies demonstrated increased choline in $\mathrm{AD}^{25-27}$ Other studies have demonstrated no change in choline concentration in $\mathrm{AD}$ compared to controls. ${ }^{28-31}$ One study reported a decrease of choline $/ \mathrm{H}_{2} 0$ in the medial temporal lobes of AD patients. ${ }^{32}$ Brain choline is concentrated in phospholipids. The choline peak in MRS represents cytosolic glycerophosphocholine and phosphocholine which are breakdown products of phosphatidylcholine. ${ }^{33}$ Therefore the larger choline peak may be due to increased membrane turnover. Also, it has been proposed that catabolism of the phospholipid membrane bilayer allows $\mathrm{AD}$ subjects to produce choline to compensate for declining acetylcholine. ${ }^{34}$ Administration of xanomeline, an M1 selective muscarinic cholinergic agonist, to $\mathrm{AD}$ patients resulted in a significant decline in $\mathrm{Cho} / \mathrm{Cr}$ ratios, perhaps representing a reduction in compensatory mechanisms to produce acetylcholine through phospholipid breakdown. ${ }^{35} \mathrm{Cho} / \mathrm{Cr}$ increases in amnestic $\mathrm{MCI}$ if it progresses to $\mathrm{AD}$ but the ratio decreases if cognition remains stable. ${ }^{36}$
Decreased glutamate (Glu) or glutamate + glutamine/Cr ratio has also been found in the grey matter of $\mathrm{AD}$ patients, but not the white matter. ${ }^{37-40}$ Furthermore, increased Glu and the ratio of Glu to $\mathrm{Cr}$ measured from the hippocampus by MRS after galantamine treatment were associated with increased cognitive performance. ${ }^{41}$ MRS studies in transgenic mice with $\mathrm{AD}$ mutations have shed light on the pathological correlates of metabolite changes seen in AD. Transgenic mice with AD mutations demonstrate similar decreased NAA and increased $\mathrm{mI}$ as seen in human $\mathrm{AD}$ patients. ${ }^{6,42}$ In addition, lower NAA and glutamate levels correlate with amyloid beta $(A \beta)$ plaque load in the frontal cortex of mice with PS2APP mutation. ${ }^{43}$ Further, the MRS metabolite changes consistent with $\mathrm{AD}$ precede overt cognitive dysfunctions in early-stage AD. ${ }^{44}$

The temporal progression of metabolite abnormalities in $\mathrm{AD}$ are characterized by an increased $\mathrm{mI} / \mathrm{Cr}$ followed by a decrease in NAA/Cr and an increase in $\mathrm{Cho} / \mathrm{Cr} .{ }^{12} \mathrm{~A}$ recent study of pathologic correlates of MRS metabolite changes in cases of varying AD pathology demonstrated that antemortem NAA/Cr and $\mathrm{mI} / \mathrm{Cr}$ levels correlate with the pathologic severity of $\mathrm{AD}$, and that the strongest predictor of $\mathrm{AD}$ pathology was a NAA $/ \mathrm{mI}$ ratio. ${ }^{45}$ Longitudinal studies have demonstrated that NAA/Cr and NAA/mI decrease over time compared to controls. . $^{36,46,47}$

$\mathrm{NAA} / \mathrm{Cr}$ and $\mathrm{mI} / \mathrm{Cr}$ ratios correlate with cognitive testing in Alzheimer's disease. ${ }^{16,17,24,48-51}$ In one study, NAA/Cr in the medial temporal lobe, primary motor and sensory cortices correlated with Mini-Mental State Examination and the cognitive part of the Alzheimer Disease Assessment Scale scores. ${ }^{16} \mathrm{NAA} / \mathrm{Cr}, \mathrm{mI} / \mathrm{Cr}$, NAA/mI have also been shown to correlate with verbal memory testing (Auditory Verbal Learning Test) and general cognition (Dementia Rating Scale). ${ }^{50}$

Several studies have investigated the ability of MRS to distinguish $\mathrm{AD}$ patients from controls with varying results depending on the anatomic area analyzed and acquisition parameters. The sensitivity was as high as $90 \%$ in the temporoparietal region and as low as $57 \%$ in the parietal lobe grey matter. The specificity was as a high as $95 \%$ in the medial occipital lobe and as low as $73 \%$ in the posterior cingulate. ${ }^{14,19,52-54}$ Furthermore, adding hippocampal volume to MRS, improves the ability to distinguish AD. ${ }^{19,53-56}$

A few studies with relatively small sample sizes have investigated MRS as a biomarker for treatment response in AD. NAA/Cr improved after acetylcholinesterase inhibitor treatment in $\mathrm{AD} .{ }^{10,28}$ Another trial showed decreases in $\mathrm{Cho} / \mathrm{Cr}$ and $\mathrm{mI} / \mathrm{Cr}$ in the hippocampus in absence of clinical 
improvement in $\mathrm{AD}$ subjects, however, this study showed continued decrease in NAA/Cr in contrast to the studies mentioned above. ${ }^{39}$

MRS also correlates with psychiatric symptoms in AD patients. AD subjects with psychosis have significantly reduced cortical NAA compared to AD subjects without psychosis. ${ }^{57}$ Psychiatric and behavioral symptoms in AD including delusional thinking correlated with a decrease in NAA/Cr and an increase in $\mathrm{mI} / \mathrm{Cr}$ in the anterior cingulate. ${ }^{58}$

\section{MRS for $\mathrm{MCl}$}

$\mathrm{NAA} / \mathrm{Cr}$ levels in MCI are mildly reduced but decline as patients with MCI progress to AD. ${ }^{36}$ Further, lower NAA/Cr in $\mathrm{MCI}$ patients predicts progression to $\mathrm{AD} .{ }^{36,59,60} \mathrm{Cho} / \mathrm{Cr}$ and $\mathrm{mI} / \mathrm{Cr}$ levels are also elevated in the posterior cingulate in MCI although higher levels of these metabolites are detected in $\mathrm{AD} .{ }^{12}$ The $\mathrm{Cho} / \mathrm{Cr}$ ratio is also useful in determining progression from MCI to AD. In MCI patients, a decline in Cho/ $\mathrm{Cr}$ predicted stability versus an increase, which predicted conversion to $\mathrm{AD}$. The changes in metabolite concentration on MRS correlate as strongly as ventricular volume in predicting cognitive decline. ${ }^{36}$

MRS is also useful in distinguishing subtypes of MCI. Amnestic MCI patients have smaller hippocampi with elevated $\mathrm{mI} / \mathrm{Cr}$ ratios compared to patients with non-amnestic MCI in line with the observation that amnestic MCI patients are more likely to progress to $\mathrm{AD}$ than non-amnestic MCI. ${ }^{61}$

\section{MRS based identification of biomarkers for other neurological disorders, to distinguish from AD}

The main differential diagnoses of Alzheimer's dementia are other types of dementia including dementia with Lewy bodies (DLB), frontotemporal dementia (FTD), and vascular dementia (VaD). The MRS signature of $\mathrm{AD}$ is decreased $\mathrm{NAA} / \mathrm{Cr}$ and elevated $\mathrm{Cho} / \mathrm{Cr}$ and $\mathrm{mI} / \mathrm{Cr}$ metabolites. ${ }^{25}$ Several studies have investigated the metabolite patterns among different types of dementia in order to identify patterns of metabolite changes unique to each dementia.

Many patients with dementia have significant overlap in underlying pathology. ${ }^{62}$ In patients with $\mathrm{VaD}$, the location of the metabolite change is important for distinguishing $\mathrm{VaD}$ from AD. For example, NAA levels in $\mathrm{VaD}$ are decreased in a similar way to those in $\mathrm{AD}$ patients and the decrease is greater than $\mathrm{AD}$ in the white matter. ${ }^{63-65}$ Unlike $\mathrm{AD}$, cortical $\mathrm{mI}$ is normal in $\mathrm{VaD} .{ }^{66,67}$ Further, $\mathrm{mI} / \mathrm{Cr}$ is higher in $\mathrm{AD}$ compared to $\mathrm{VaD} .{ }^{25}$ Therefore, $\mathrm{mI}$ and grey matter NAA may serve as useful markers to distinguish $\mathrm{AD}$ from $\mathrm{VaD}$.
Similar to AD, FTD is associated with elevated $\mathrm{mI} / \mathrm{Cr}$ and decreased NAA/Cr. ${ }^{68,69}$ Despite the similarities, regional differences in metabolites may help distinguish the two dementias. Compared to early AD, patients with FTD have higher $\mathrm{mI} / \mathrm{Cr}$ and lower NAA/Cr in the frontal cortex. ${ }^{68,70}$ However, others have noted no difference between FTD and AD with similar levels of metabolite abnormalities outside the frontal lobes. ${ }^{25}$

Similar to the other dementias, significant overlap exists between DLB and AD. Compared to other dementia subtypes, DLB has a normal NAA/Cr ratio in the posterior cingulate. ${ }^{25}$ The normal NAA/Cr is possibly related to the relative preservation of neurons in DLB compared to AD. ${ }^{71}$ In the hippocampus of DLB patients, the NAA has been reported to be decreased although it is unclear if this decrease represents concomitant $\mathrm{AD}$ given the overlap in pathologies mentioned above. ${ }^{72}$ Additionally, NAA is similarly decreased in the white matter of patients with DLB. ${ }^{73}$ Therefore, NAA levels in the posterior cingulate may help distinguish $A D$ from DLB. The relative preservation of the cingulate is in agreement with fluorodeoxyglucose (FDG) positron emission tomography (PET) which demonstrates a relative preservation of glucose metabolism in the cingulate of DLB when compared to $\mathrm{AD} .{ }^{74}$

Similar to AD, DLB patients have an elevated $\mathrm{Cho} / \mathrm{Cr}$ compared to controls. ${ }^{25}$ This finding is intriguing because both AD and DLB are characterized by a cholinergic deficit. ${ }^{75}$ Since $\mathrm{Cho} / \mathrm{Cr}$ levels decrease with cholinergic agonist treatment in $\mathrm{AD},{ }^{35}$ the decrease raises the possibility that $\mathrm{Cho} / \mathrm{Cr}$ can be used as a therapeutic biomarker in AD and DLB.

In summary, while significant overlap exists between dementias, $\mathrm{AD}$ has a unique metabolite pattern compared to other dementias when regional differences are taken into account.

\section{Current place of MRS in the differential diagnosis of AD}

The American Academy of Neurology practice parameter recommends against routine imaging with quantitative MRI techniques in the evaluation of dementia because of insufficient evidence. ${ }^{76}$ Nonetheless, as a research tool, MRS can provide valuable information in the differential diagnoses of dementia. AD biomarkers, such as Amyloid PET imaging and cerebrospinal fluid $\mathrm{A} \beta$, provide useful information about whether $\mathrm{AD}$ is the pathology underlying a given dementia. MRS can provide complementary predictive information. In addition, MRS allows for identification of a metabolite signature of different dementia subtypes which can provide 


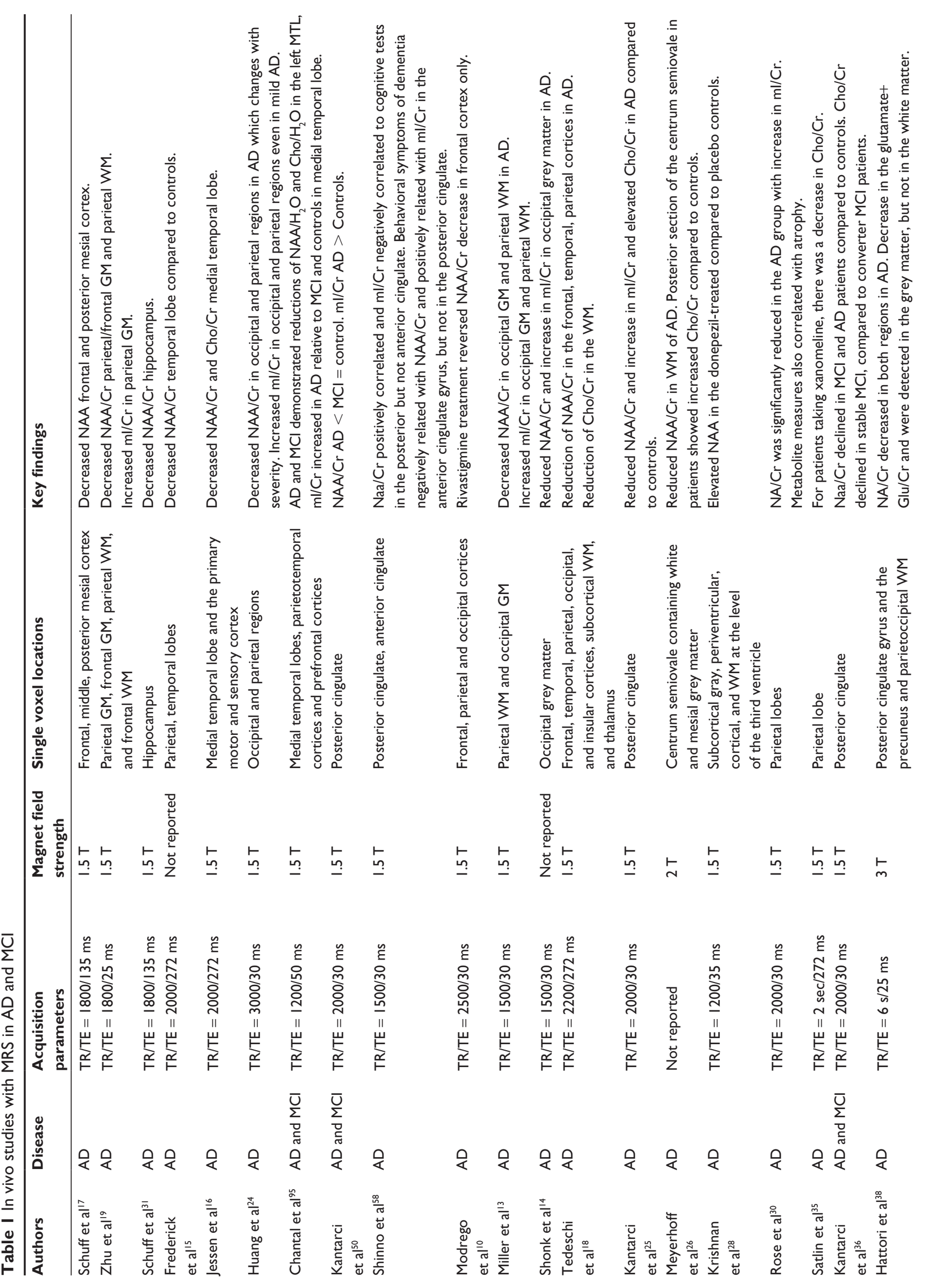



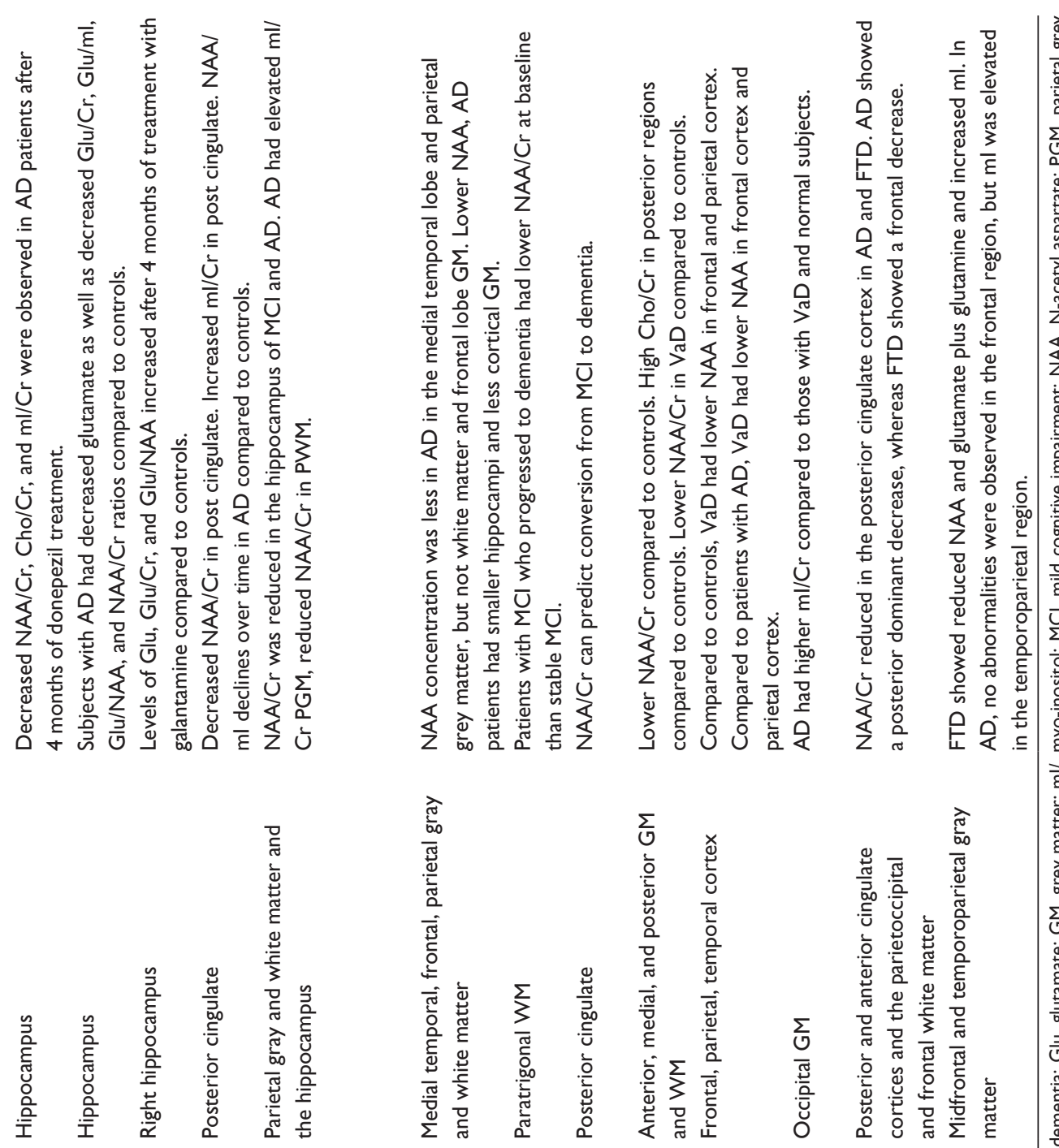

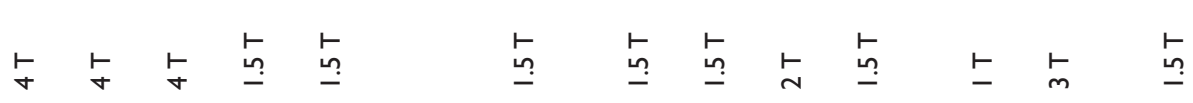

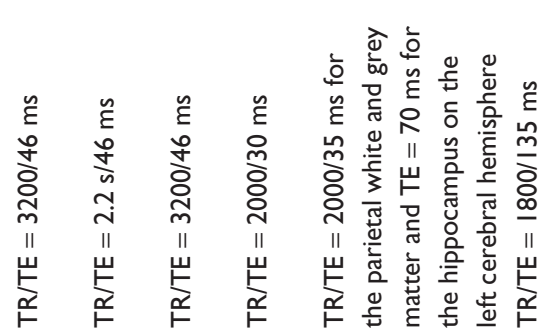

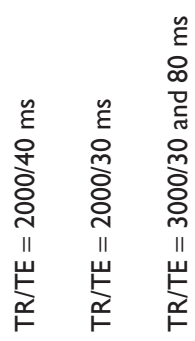

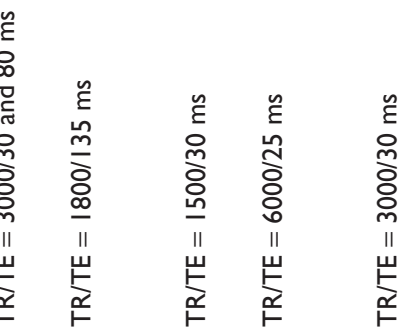

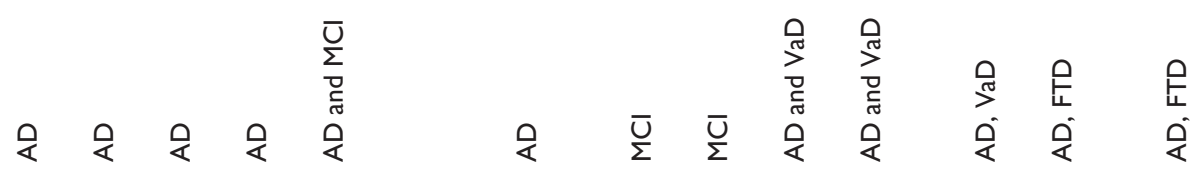

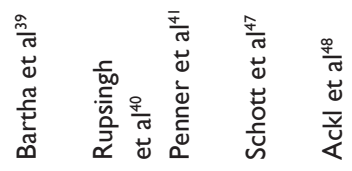

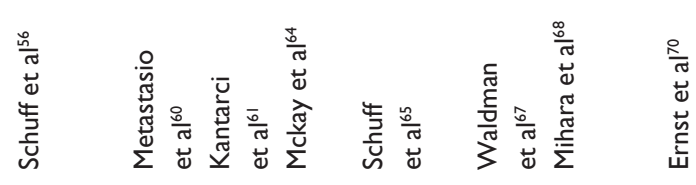

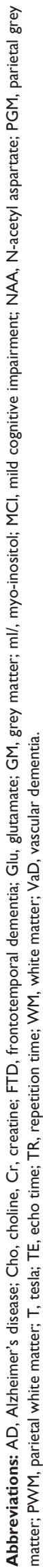


complementary data to the clinical impression. To date, no MRS study has used metabolite signature in conjunction with regional differences to determine the underlying pathology.

\section{Utility of MRS along with other AD biomarkers}

In 2011, the National Institute on Aging and Alzheimer's Association revised criteria for preclinical, MCI, and Alzheimer's disease. ${ }^{77-80}$ The pathology that contributes to AD begins to accumulate years before clinical symptoms. Therefore, identifying the population at high risk of developing symptoms has become important. Principal AD imaging biomarkers include $\mathrm{A} \beta$ imaging with PET, FDG-PET, and structural MRI. In cognitively normal older adults, $\mathrm{mI} / \mathrm{Cr}$ and $\mathrm{Cho} / \mathrm{Cr}$ correlate with $\mathrm{A} \beta$ load in amyloid PET imaging as demonstrated in two example cases with high and low $\mathrm{A} \beta$ load in their brains in Figure $1 .^{81}$

According to one model of biomarkers in AD, amyloid pathology accumulates before evidence of neurodegeneration. ${ }^{82}$ Amyloid PET imaging serves as a surrogate for brain amyloid load and FDG-PET and Structural MRI serve as markers of neurodegeneration. While these imaging markers are well validated measures of amyloid and neurofibrillary tangle pathology, they do not measure microglial activation. MRS $\mathrm{mI}$ is a potential surrogate marker for glial activity. A recent 13-carbon MRS and ${ }^{1} \mathrm{H}$ MRS linked glial and microglial activity to $\mathrm{mI}$ elevation in $\mathrm{AD}{ }^{83}$

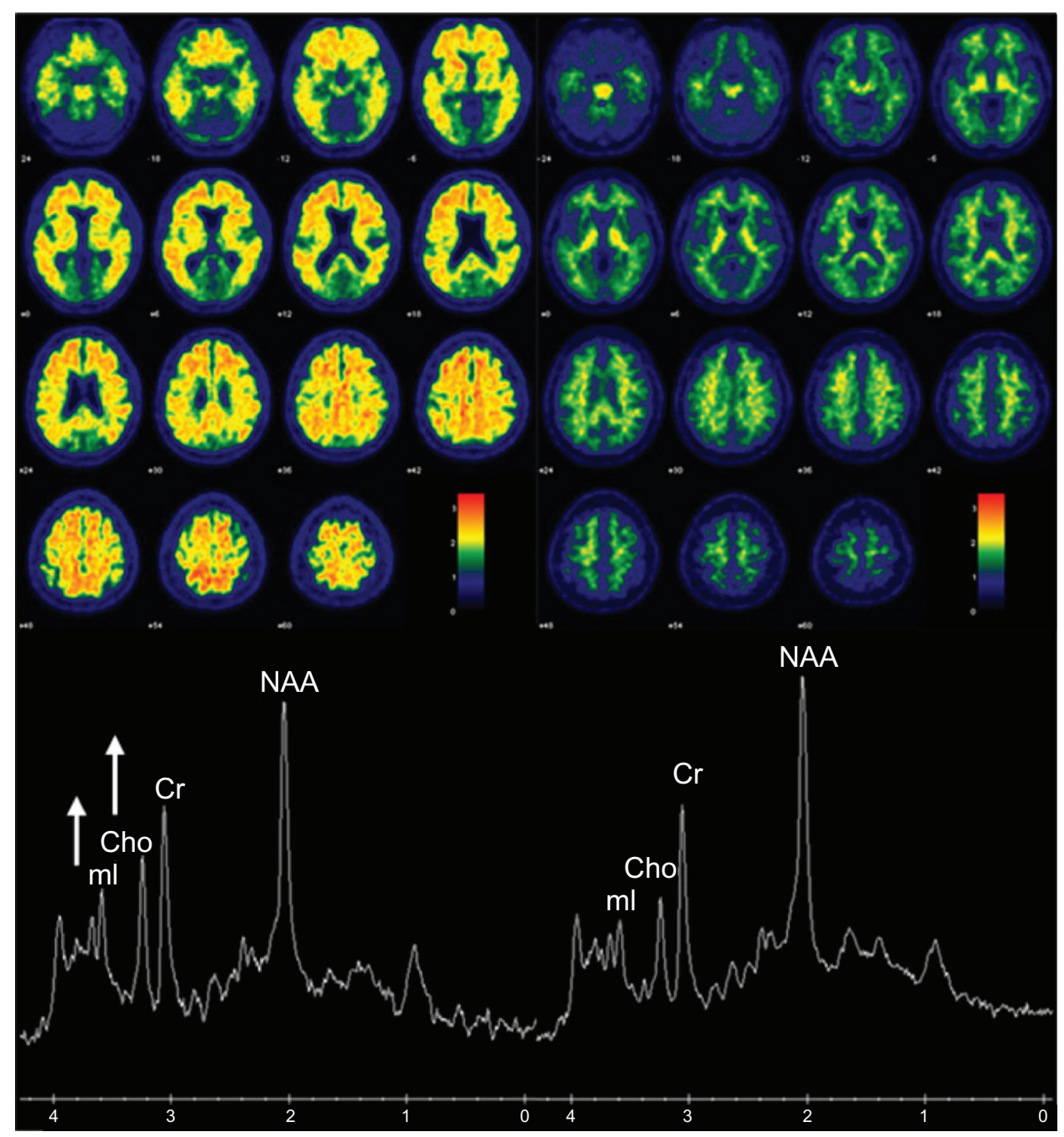

Figure I Association between MRS metabolite ratios and cortical Pittsburgh compound-B (PiB) retention ratio on PET.

Notes: The left panel shows the PiB retention ratio PET images in an 82-year-old man with a PiB retention ratio of 2.42 , NAA/Cr ratio of I.5I, ml/Cr ratio of 0.58 , and $\mathrm{Cho} / \mathrm{Cr}$ ratio of 0.76 . The right panel shows the $\mathrm{PiB}$ retention ratio in a 78 year-old woman with a PiB retention ratio $\mathrm{PET}$ images of $\mathrm{I.27}$, NAA/Cr ratio of $\mathrm{I} .69$, ml/Cr ratio of 0.45 , and $\mathrm{Cho} / \mathrm{Cr}$ ratio of 0.54 . The spectra are scaled to the $\mathrm{Cr}$ peak. High $\mathrm{PiB}$ retention is associated with significantly elevated $\mathrm{ml} / \mathrm{Cr}$ and $\mathrm{Cho} / \mathrm{Cr}$ ratio and a trend of lower NAA/Cr ratio.

Abbreviations: Cho, choline; Cr, creatine; ml, myo-inositol; MRS, magnetic resonance spectroscopy; NAA, N-acetyl aspartate; PET, positron emission tomography. 
This raises the possibility that elevated $\mathrm{mI}$ represents inflammation which is an early event in the evolution of AD pathology. ${ }^{2}$

While hippocampal atrophy predicts AD pathology and is an imaging marker of neurodegeneration in the National Institute on Aging - Alzheimer's Association (criteria for preclinical AD), ${ }^{84,85}$ up to $11 \%$ of AD cases are hippocampal sparing, with corresponding preserved hippocampal volumes on MRI. ${ }^{86,87}$ Subjects with at least one type of hippocampal sparing AD (posterior cortical atrophy), have been demonstrated to have decreased NAA/Cr in the posterior cingulate. ${ }^{88}$ Therefore, MRS may serve a role as a critical marker of AD pathology in a significant minority of $\mathrm{AD}$ cases where the hippocampus is relatively preserved. Other imaging markers that may provide important information in atypical AD cases include resting state functional MRI, and diffusion tensor imaging (DTI). Cognitive testing may provide additional information.

MRS can serve as a predictor of the degree of AD pathology in clinical trial design. For example, $\mathrm{mI} / \mathrm{Cr}$ is elevated in MCI and mild AD even with normal NAA/Cr. ${ }^{12,24,89}$ In addition, isolated $\mathrm{mI} / \mathrm{Cr}$ elevation is associated with earlier stage $\mathrm{AD}$ pathology compared to elevated $\mathrm{mI}$ and decrease in $\mathrm{NAA} / \mathrm{Cr}$ which is associated with a later stage AD pathology. Isolated elevation in $\mathrm{mI} / \mathrm{Cr}$ can be seen prior to structural MRI changes in individuals with familial dementia prior to symptom onset..$^{90}$ Therefore, MRS could potentially serve as an adjunct to help select patients for intervention trials based on degree of AD pathology.

In addition to serving as a potential marker of glial activity, MRS can be used along with other biomarkers as a tool to predict cognitive decline. In a group of cognitively normal individuals, elevated $\mathrm{Cho} / \mathrm{Cr}$ in the white matter predicts progression to dementia. ${ }^{91}$ The metabolite formula changes in preclinical familial AD families with amyloid precursor protein, presenilin 1 or 2 mutations. Asymptomatic mutation carriers demonstrated elevated $\mathrm{mI} / \mathrm{Cr}$ and decreased NAA/Cr with reduction in NAA/mI correlating with nearness to age of onset. ${ }^{92}$ In addition to serving as a marker of preclinical disease, MRS has utility in monitoring disease progression. NAA/Cr levels predict cognitive decline in individuals with $\mathrm{AD}{ }^{36,46,93}$

\section{Future predictions for the use of MRS in the differential diagnosis of AD}

While much progress has been made in understanding the role of MRS in Alzheimer's disease, MRS is still not routinely used clinically in the assessment of dementia. Reasons for ineffective translation of technology to clinical practice or patient-oriented research are twofold: (1) Lack of standardization for multi-site applications and normative data; and (2) insufficient understanding of the pathologic basis of ${ }^{1} \mathrm{H}$ MRS metabolite changes. ${ }^{94}$ Although metabolite abnormalities in AD have been demonstrated in different samples and in pathologically confirmed cases, the pathological substrates for these metabolite abnormalities are not fully understood. Future studies are needed to elucidate the pathological significance of these metabolite changes in AD. As we learn more about the pathophysiologic underpinnings of the metabolite abnormalities, the routine use of MRS as a biomarker will become more prevalent.

\section{Acknowledgment}

Grant support: Dr Kantarci's research program is supported by the National Institutes of Health: R01 AG40042, P50 AG16574/Project1, P50AG044170/Project 2, and R21 NS066147. The authors would like to acknowledge Samantha Wille for manuscript preparation.

\section{Disclosure}

Dr Kantarci serves on the data safety monitoring board for Pfizer Inc, and Janssen Amyloid Immunotherapy and Takeda Global Research and Development Center, Inc; she is funded by the National Institutes of Health (R01AG040042 [PI], R21 NS066147 [PI], P50 AG44170/Project 2 [PI], P50 AG16574/Project 1 [PI], and R01 AG11378 [Co-I]).

Dr Graff-Radford reports no conflicts of interest in this work.

\section{References}

1. Kantarci K. 1H magnetic resonance spectroscopy in dementia. $\mathrm{Br} \mathrm{J}$ Radiol. 2007;80 Spec No 2:S146-S152.

2. Ross BD, Bluml S, Cowan R, Danielsen E, Farrow N, Tan J. In vivo MR spectroscopy of human dementia. Neuroimaging Clin $\mathrm{N} \mathrm{Am}$. 1998;8(4):809-822.

3. Valenzuela MJ, Sachdev P. Magnetic resonance spectroscopy in AD. Neurology. 2001;56(5):592-598.

4. Klunk WE, Panchalingam K, Moossy J, McClure RJ, Pettegrew JW. $\mathrm{N}$-acetyl-L-aspartate and other amino acid metabolites in Alzheimer's disease brain: a preliminary proton nuclear magnetic resonance study. Neurology. 1992;42(8):1578-1585.

5. Bates TE, Strangward M, Keelan J, Davey GP, Munro PM, Clark JB. Inhibition of $\mathrm{N}$-acetylaspartate production: implications for $1 \mathrm{H}$ MRS studies in vivo. Neuroreport. 1996;7(8):1397-1400.

6. Cheng LL, Newell K, Mallory AE, Hyman BT, Gonzalez RG. Quantification of neurons in Alzheimer and control brains with ex vivo high resolution magic angle spinning proton magnetic resonance spectroscopy and stereology. Magn Reson Imaging. 2002;20(7):527-533.

7. Brooks WM, Stidley CA, Petropoulos H, et al. Metabolic and cognitive response to human traumatic brain injury: a quantitative proton magnetic resonance study. J Neurotrauma. 2000;17(8):629-640. 
8. Bendszus M, Reents W, Franke D, et al. Brain damage after coronary artery bypass grafting. Arch Neurol. 2002;59(7):1090-1095.

9. Hugg JW, Kuzniecky RI, Gilliam FG, Morawetz RB, Fraught RE, Hetherington HP. Normalization of contralateral metabolic function following temporal lobectomy demonstrated by $1 \mathrm{H}$ magnetic resonance spectroscopic imaging. Ann Neurol. 1996;40(2):236-239.

10. Modrego PJ, Pina MA, Fayed N, Diaz M. Changes in metabolite ratios after treatment with rivastigmine in Alzheimer's disease: a nonrandomised controlled trial with magnetic resonance spectroscopy. CNS Drugs. 2006;20(10):867-877.

11. Braak H, Braak E. Neuropathological stageing of Alzheimer-related changes. Acta Neuropathologica. 1991;82(4):239-259.

12. Kantarci K, Jack CR Jr, Xu YC, et al. Regional metabolic patterns in mild cognitive impairment and Alzheimer's disease: A 1H MRS study. Neurology. 2000;55(2):210-217.

13. Miller BL, Moats RA, Shonk T, Ernst T, Woolley S, Ross BD. Alzheimer disease: depiction of increased cerebral myo-inositol with proton MR spectroscopy. Radiology. 1993;187(2):433-437.

14. Shonk TK, Moats RA, Gifford P, et al. Probable Alzheimer disease: diagnosis with proton MR spectroscopy. Radiology. 1995;195(1):65-72.

15. Frederick BB, Satlin A, Yurgelun-Todd DA, Renshaw PF. In vivo proton magnetic resonance spectroscopy of Alzheimer's disease in the parietal and temporal lobes. Biol Psychiatry. 1997;42(2):147-150.

16. Jessen F, Block W, Traber F, et al. Proton MR spectroscopy detects a relative decrease of $\mathrm{N}$-acetylaspartate in the medial temporal lobe of patients with AD. Neurology. 2000;55(5):684-688.

17. Schuff N, Amend DL, Meyerhoff DJ, et al. Alzheimer disease: quantitative $\mathrm{H}-1$ MR spectroscopic imaging of frontoparietal brain. Radiology. 1998;207(1):91-102.

18. Tedeschi G, Bertolino A, Lundbom N, et al. Cortical and subcortical chemical pathology in Alzheimer's disease as assessed by multislice proton magnetic resonance spectroscopic imaging. Neurology. 1996;47(3):696-704.

19. Zhu X, Schuff N, Kornak J, et al. Effects of Alzheimer disease on fronto-parietal brain $\mathrm{N}$-acetyl aspartate and myo-inositol using magnetic resonance spectroscopic imaging. Alzheimer Dis Assoc Disord. 2006;20(2):77-85.

20. Shiino A, Matsuda M, Morikawa S, Inubushi T, Akiguchi I, Handa J. Proton magnetic resonance spectroscopy with dementia. Surg Neurol. 1993;39(2):143-147.

21. Barker PB, Lee RR, McArthur JC. AIDS dementia complex: evaluation with proton MR spectroscopic imaging. Radiology. 1995;195(1): $58-64$

22. Bitsch A, Bruhn H, Vougioukas V, et al. Inflammatory CNS demyelination: histopathologic correlation with in vivo quantitative proton MR spectroscopy. AJNR Am J Neuroradiol. 1999;20(9):1619-1627.

23. Glanville NT, Byers DM, Cook HW, Spence MW, Palmer FB. Differences in the metabolism of inositol and phosphoinositides by cultured cells of neuronal and glial origin. Biochimica et Biophysica Acta. 1989;1004(2):169-179.

24. Huang W, Alexander GE, Chang L, et al. Brain metabolite concentration and dementia severity in Alzheimer's disease: a (1)H MRS study. Neurology. 2001;57(4):626-632.

25. Kantarci K, Petersen RC, Boeve BF, et al. 1H MR spectroscopy in common dementias. Neurology. 2004;63(8):1393-1398.

26. Meyerhoff DJ, MacKay S, Constans JM, et al. Axonal injury and membrane alterations in Alzheimer's disease suggested by in vivo proton magnetic resonance spectroscopic imaging. Ann Neurol. 1994;36(1):40-47.

27. Pfefferbaum A, Adalsteinsson E, Spielman D, Sullivan EV, Lim KO. In vivo spectroscopic quantification of the $\mathrm{N}$-acetyl moiety, creatine, and choline from large volumes of brain gray and white matter: effects of normal aging. Magn Reson Med. 1999;41(2):276-284.

28. Krishnan KR, Charles HC, Doraiswamy PM, et al. Randomized, placebo-controlled trial of the effects of donepezil on neuronal markers and hippocampal volumes in Alzheimer's disease. Am J Psychiatry. 2003;160(11):2003-2011.
29. Moats RA, Ernst T, Shonk TK, Ross BD. Abnormal cerebral metabolite concentrations in patients with probable Alzheimer disease. Magn Reson Med. 1994;32(1):110-115.

30. Rose SE, de Zubicaray GI, Wang D, et al. A 1H MRS study of probable Alzheimer's disease and normal aging: implications for longitudinal monitoring of dementia progression. Magn Reson Imaging. 1999;17(2):291-299.

31. Schuff N, Amend D, Ezekiel F, et al. Changes of hippocampal N-acetyl aspartate and volume in Alzheimer's disease. A proton MR spectroscopic imaging and MRI study. Neurology. 1997;49(6):1513-1521.

32. Chantal S, Labelle M, Bouchard RW, Braun CM, Boulanger Y. Correlation of regional proton magnetic resonance spectroscopic metabolic changes with cognitive deficits in mild Alzheimer disease. Arch Neurol. 2002;59(6):955-962.

33. Klein J. Membrane breakdown in acute and chronic neurodegeneration: focus on choline-containing phospholipids. J Neural Transm. 2000;107(8-9):1027-1063.

34. Wurtman RJ, BJ, Marie JC. "Autocannibalism" of choline-containing membrane phospholipids in the pathogenesis of Alzheimer's disease. Neurochem Int. 1985;7:369-372.

35. Satlin A, Bodick N, Offen WW, Renshaw PF. Brain proton magnetic resonance spectroscopy (1H-MRS) in Alzheimer's disease: changes after treatment with xanomeline, an M1 selective cholinergic agonist. Am J Psychiatry. 1997;154(10):1459-1461

36. Kantarci K, Weigand SD, Petersen RC, et al. Longitudinal 1H MRS changes in mild cognitive impairment and Alzheimer's disease. Neurobiol Aging. 2007;28(9):1330-1339.

37. Antuono PG, Jones JL, Wang Y, Li SJ. Decreased glutamate + glutamine in Alzheimer's disease detected in vivo with (1)H-MRS at $0.5 \mathrm{~T}$. Neurology. 2001;56(6):737-742.

38. Hattori N, Abe K, Sakoda S, Sawada T. Proton MR spectroscopic study at 3 Tesla on glutamate/glutamine in Alzheimer's disease. Neuroreport. 2002;13(1):183-186.

39. Bartha R, Smith M, Rupsingh R, Rylett J, Wells JL, Borrie MJ. High field (1)H MRS of the hippocampus after donepezil treatment in Alzheimer disease. Prog Neuropsychopharmacol Biol Psychiatry. 2008; 32(3):786-793.

40. Rupsingh R, Borrie M, Smith M, Wells JL, Bartha R. Reduced hippocampal glutamate in Alzheimer disease. Neurobiol Aging. 2011;32(5): 802-810.

41. Penner J, Rupsingh R, Smith M, Wells JL, Borrie MJ, Bartha R. Increased glutamate in the hippocampus after galantamine treatment for Alzheimer disease. Prog Neuro-Psychopharmacol Biol Psychiatry. 2010;34(1):104-110.

42. Chen SQ, Wang PJ, Ten GJ, Zhan W, Li MH, Zang FC. Role of myo-inositol by magnetic resonance spectroscopy in early diagnosis of Alzheimer's disease in APP/PS1 transgenic mice. Dement Geriatr Cogn Disord. 2009;28(6):558-566.

43. von Kienlin M, Kunnecke B, Metzger F, et al. Altered metabolic profile in the frontal cortex of PS2 APP transgenic mice, monitored throughout their life span. Neurobiol Dis. 2005;18(1):32-39.

44. Chen SQ, Cai Q, Shen YY, et al. Age-related changes in brain metabolites and cognitive function in APP/PS1 transgenic mice. Behav Brain Res. 2012;235(1):1-6.

45. Kantarci K, Knopman DS, Dickson DW, et al. Alzheimer disease: postmortem neuropathologic correlates of antemortem 1H MR spectroscopy metabolite measurements. Radiology. 2008;248(1):210-220.

46. Jessen F, Block W, Traber F, et al. Decrease of N-acetylaspartate in the MTL correlates with cognitive decline of AD patients. Neurology. 2001;57(5):930-932.

47. Schott JM, Frost C, MacManus DG, Ibrahim F, Waldman AD, Fox NC. Short echo time proton magnetic resonance spectroscopy in Alzheimer's disease: a longitudinal multiple time point study. Brain. 2010;133(11): $3315-3322$.

48. Ackl N, Ising M, Schreiber YA, Atiya M, Sonntag A, Auer DP. Hippocampal metabolic abnormalities in mild cognitive impairment and Alzheimer's disease. Neurosci Lett. 2005;384(1-2):23-28. 
49. Doraiswamy PM, Charles HC, Krishnan KR. Prediction of cognitive decline in early Alzheimer's disease. Lancet. 1998;352(9141):1678.

50. Kantarci K, Smith GE, Ivnik RJ, et al. 1H magnetic resonance spectroscopy, cognitive function, and apolipoprotein E genotype in normal aging, mild cognitive impairment and Alzheimer's disease. $J$ Int Neuropsychol Soc. 2002;8(7):934-942.

51. Kwo-On-Yuen PF, Newmark RD, Budinger TF, Kaye JA, Ball MJ, Jagust WJ. Brain N-acetyl-L-aspartic acid in Alzheimer's disease: a proton magnetic resonance spectroscopy study. Brain Res. 1994 667(2):167-174

52. Fernandez A, Garcia-Segura JM, Ortiz T, et al. Proton magnetic resonance spectroscopy and magnetoencephalographic estimation of delta dipole density: a combination of techniques that may contribute to the diagnosis of Alzheimer's disease. Dement Geriatr Cogn Disord. 2005;20(2-3):169-177.

53. Kantarci K, Xu Y, Shiung MM, et al. Comparative diagnostic utility of different MR modalities in mild cognitive impairment and Alzheimer's disease. Dement Geriatr Cogn Disord. 2002;14(4):198-207.

54. Martinez-Bisbal MC, Arana E, Marti-Bonmati L, Molla E, Celda B. Cognitive impairment: classification by $1 \mathrm{H}$ magnetic resonance spectroscopy. Eur J Neurol. 2004;11(3):187-193.

55. MacKay S, Ezekiel F, Di Sclafani V, et al. Alzheimer disease and subcortical ischemic vascular dementia: evaluation by combining MR imaging segmentation and H-1 MR spectroscopic imaging. Radiology. 1996;198(2):537-545.

56. Schuff N, Capizzano AA, Du AT, et al. Selective reduction of $\mathrm{N}$-acetylaspartate in medial temporal and parietal lobes in $\mathrm{AD}$ Neurology. 2002;58(6):928-935.

57. Sweet RA, Panchalingam K, Pettegrew JW, et al. Psychosis in Alzheimer disease: postmortem magnetic resonance spectroscopy evidence of excess neuronal and membrane phospholipid pathology. Neurobiol Aging. 2002;23(4):547-553.

58. Shinno H, Inagaki T, Miyaoka $\mathrm{T}$, et al. A decrease in $\mathrm{N}$-acetylaspartate and an increase in myoinositol in the anterior cingulate gyrus are associated with behavioral and psychological symptoms in Alzheimer's disease. J Neurol Sci. 2007;260(1-2):132-138.

59. Chao LL, Schuff N, Kramer JH, et al. Reduced medial temporal lobe $\mathrm{N}$-acetylaspartate in cognitively impaired but nondemented patients Neurology. 2005;64(2):282-289.

60. Metastasio A, Rinaldi P, Tarducci R, et al. Conversion of MCI to dementia: role of proton magnetic resonance spectroscopy. Neurobiol Aging. 2006;27(7):926-932.

61. Kantarci K, Weigand SD, Przybelski SA, et al. Risk of dementia in MCI: combined effect of cerebrovascular disease, volumetric MRI, and 1H MRS. Neurology. 2009;72(17):1519-1525.

62. Schneider JA, Arvanitakis Z, Bang W, Bennett DA. Mixed brain pathologies account for most dementia cases in community-dwelling older persons. Neurology. 2007;69(24):2197-2204.

63. Kattapong VJ, Brooks WM, Wesley MH, Kodituwakku PW, Rosenberg GA. Proton magnetic resonance spectroscopy of vascularand Alzheimer-type dementia. Arch Neurol. 1996;53(7):678-680.

64. MacKay S, Meyerhoff DJ, Constans JM, Norman D, Fein G, Weiner MW. Regional gray and white matter metabolite differences in subjects with $\mathrm{AD}$, with subcortical ischemic vascular dementia, and elderly controls with $1 \mathrm{H}$ magnetic resonance spectroscopic imaging. Arch Neurol. 1996;53(2):167-174.

65. Schuff N, Capizzano AA, Du AT, et al. Different patterns of $\mathrm{N}$-acetylaspartate loss in subcortical ischemic vascular dementia and AD. Neurology. 2003;61(3):358-364.

66. Shiino A, Watanabe T, Shirakashi Y, et al. The profile of hippocampal metabolites differs between Alzheimer's disease and subcortical ischemic vascular dementia, as measured by proton magnetic resonance spectroscopy. J Cereb Blood Flow Metab. 2012;32(5):805-815.

67. Waldman AD, Rai GS, McConnell JR, Chaudry M, Grant D. Clinical brain proton magnetic resonance spectroscopy for management of Alzheimer's and sub-cortical ischemic vascular dementia in older people. Arch Gerontol Geriatr. 2002;35(2):137-142.
68. Mihara M, Hattori N, Abe K, Sakoda S, Sawada T. Magnetic resonance spectroscopic study of Alzheimer's disease and frontotemporal dementia/Pick complex. Neuroreport. 2006;17(4):413-416.

69. Shonk TK, Moats RA, Gifford P, et al. Probable Alzheimer disease: diagnosis with proton MR spectroscopy. [see comment]. Radiology. 1995;195(1):65-72.

70. Ernst T, Chang L, Melchor R, Mehringer CM. Frontotemporal dementia and early Alzheimer disease: differentiation with frontal lobe H-1 MR spectroscopy. Radiology. 1997;203(3):829-836.

71. Gomez-Isla T, Growdon WB, McNamara M, et al. Clinicopathologic correlates in temporal cortex in dementia with Lewy bodies. Neurology. 1999;53(9):2003-2009.

72. Xuan X, Ding M, Gong X. Proton magnetic resonance spectroscopy detects a relative decrease of $\mathrm{N}$-acetylaspartate in the hippocampus of patients with dementia with Lewy bodies. $J$ Neuroimaging. 2008; 18(2):137-141.

73. Molina JA, Garcia-Segura JM, Benito-Leon J, et al. Proton magnetic resonance spectroscopy in dementia with Lewy bodies. Eur Neurol. 2002;48(3):158-163.

74. Lim SM, Katsifis A, Villemagne VL, et al. The 18F-FDG PET cingulate island sign and comparison to 123I-beta-CIT SPECT for diagnosis of dementia with Lewy bodies. J Nucl Med. 2009;50(10):1638-1645.

75. Tiraboschi P, Hansen LA, Alford M, et al. Early and widespread cholinergic losses differentiate dementia with Lewy bodies from Alzheimer disease. Arch Gen Psychiatry. 2002;59(10):946-951.

76. Knopman DS, DeKosky ST, Cummings JL, et al. Practice parameter: diagnosis of dementia (an evidence-based review). Report of the Quality Standards Subcommittee of the American Academy of Neurology. [see comment]. Neurology. 2001;56(9):1143-1153.

77. Albert MS, DeKosky ST, Dickson D, et al. The diagnosis of mild cognitive impairment due to Alzheimer's disease: recommendations from the National Institute on Aging-Alzheimer's Association workgroups on diagnostic guidelines for Alzheimer's disease. Alzheimers Dement. 2011;7(3):270-279.

78. Jack CR Jr, Albert MS, Knopman DS, et al. Introduction to the recommendations from the National Institute on Aging-Alzheimer's Association workgroups on diagnostic guidelines for Alzheimer's disease. Alzheimers Dement. 2011;7(3):257-262.

79. McKhann GM, Knopman DS, Chertkow H, et al. The diagnosis of dementia due to Alzheimer's disease: recommendations from the National Institute on Aging-Alzheimer's Association workgroups on diagnostic guidelines for Alzheimer's disease. Alzheimers Dement. 2011;7(3):263-269.

80. Ross AJ, Sachdev PS, Wen W, Valenzuela MJ, Brodaty H. 1H MRS in stroke patients with and without cognitive impairment. Neurobiol Aging. 2005;26(6):873-882.

81. Kantarci K, Lowe V, Przybelski SA, et al. Magnetic resonance spectroscopy, beta-amyloid load, and cognition in a population-based sample of cognitively normal older adults. Neurology. 2011;77(10):951-958.

82. Jack CR Jr, Knopman DS, Jagust WJ, et al. Hypothetical model of dynamic biomarkers of the Alzheimer's pathological cascade. Lancet Neurol. 2010;9(1):119-128.

83. Sailasuta N, Harris K, Tran T, Ross B. Minimally invasive biomarker confirms glial activation present in Alzheimer's disease: a preliminary study. Neuropsychiatr Dis Treat. 2011;7:495-499.

84. Jack CR Jr, Dickson DW, Parisi JE, et al. Antemortem MRI findings correlate with hippocampal neuropathology in typical aging and dementia. Neurology. 2002;58(5):750-757.

85. Sperling RA, Aisen PS, Beckett LA, et al. Toward defining the preclinical stages of Alzheimer's disease: recommendations from the National Institute on Aging-Alzheimer's Association workgroups on diagnostic guidelines for Alzheimer's disease. Alzheimers Dement. 2011;7(3):280-292.

86. Murray ME, Graff-Radford NR, Ross OA, Petersen RC, Duara R, Dickson DW. Neuropathologically defined subtypes of Alzheimer's disease with distinct clinical characteristics: a retrospective study. Lancet Neurol. 2011;10(9):785-796. 
87. Whitwell JL, Dickson DW, Murray ME, et al. Neuroimaging correlates of pathologically defined subtypes of Alzheimer's disease: a casecontrol study. Lancet Neurol. 2012;11(10):868-877.

88. Whitwell JL, Jack CR Jr, Kantarci K, et al. Imaging correlates of posterior cortical atrophy. Neurobiol Aging. 2007;28(7):1051-1061.

89. Catani M, Cherubini A, Howard R, et al. (1)H-MR spectroscopy differentiates mild cognitive impairment from normal brain aging. Neuroreport. 2001;12(11):2315-2317.

90. Kantarci K, Boeve BF, Wszolek ZK, et al. MRS in presymptomatic MAPT mutation carriers: a potential biomarker for tau-mediated pathology. Neurology. 2010;75(9):771-778.

91. den Heijer T, Sijens PE, Prins ND, et al. MR spectroscopy of brain white matter in the prediction of dementia. Neurology. 2006;66(4): 540-544.
92. Godbolt AK, Waldman AD, MacManus DG, et al. MRS shows abnormalities before symptoms in familial Alzheimer disease. Neurology. 2006;66(5):718-722.

93. Adalsteinsson E, Sullivan EV, Kleinhans N, Spielman DM, PfefferbaumA. Longitudinal decline of the neuronal marker N-acetyl aspartate in Alzheimer's disease. Lancet. 2000;355(9216):1696-1697.

94. Kantarci K. Proton MRS in mild cognitive impairment. J Magn Reson Imaging. 2013;37(4):770-777.

95. Chantal S, Braun CM, Bouchard RW, Labelle M, Boulanger Y. Similar $1 \mathrm{H}$ magnetic resonance spectroscopic metabolic pattern in the medial temporal lobes of patients with mild cognitive impairment and Alzheimer disease. Brain Res. 2004;1003(1-2): 26-35.

\section{Publish your work in this journal}

Neuropsychiatric Disease and Treatment is an international, peerreviewed journal of clinical therapeutics and pharmacology focusing on concise rapid reporting of clinical or pre-clinical studies on a range of neuropsychiatric and neurological disorders. This journal is indexed on PubMed Central, the 'PsycINFO' database and CAS.
The manuscript management system is completely online and includes a very quick and fair peer-review system, which is all easy to use. Visit http://www.dovepress.com/testimonials.php to read real quotes from published authors.

Submit your manuscript here: http://www.dovepress.com/neuropsychiatric-disease-and-treatment-journal 